American Journal of Applied Sciences 8 (9): 910-917, 2011

ISSN 1546-9239

(C) 2011 Science Publications

\title{
Inheritance based Intelligent Technique Employing Nested-XOR with Recursion for Recognition and Classification of Odors using Multi-Sensor Nose System
}

\author{
Mahmoud Z. Iskandarani \\ Department of Computer Science, \\ Faculty of Science and Information Technology, \\ Al-Zaytoonah University of Jordan
}

\begin{abstract}
Problem statement: Odor originality and fraud is an important issue in today's world. In addition knowing the original material that an odor belongs to even after being mixed with others is also of vital importance. In addition measuring quality of mixed odors in terms of their affinity and belonging to a specific category or is critical. Approach: Design, testing and analysis of multi-sensor odor system for the objectives of odor recognition, classification and correlation are carried out. Results: Various mixtures are tested and checked for originality through inheritance using The built multi-sensor electronic nose. The testing devices and interpretation using Nested-XOR based algorithm with recursion showed clearly some odors to be related to others or derived from the same source. Conclusion/Recommendations: Clear evidence of ability to trace components of an odor mixture and to determine its originality and quality.
\end{abstract}

Key words: Odor sensor, odor discrimination, trace components, specific category, various mixtures, gas sensors, great deal, particular sample

\section{INTRODUCTION}

Since the first applications of solid state gas sensors in arrays, electronic noses went through a great deal of development. Many articles on this subject have been published over the last few years, mainly in relation to the food and beverage industry, but also concerning environmental, agricultural, medical topics and automotive industry, among others. However, the number of studies dedicated to nose based odor originality systems is still very limited, probably due to the complexity of their matrices.

The potential uses of nose-machines, which essentially mimic the functions of human noses but with more precision, are endless. Perfume makers are already using them to protect their patented smells against fake-fragrance merchants and inspectors have used a high-tech nose for grading of fish freshness. More exciting are the possible medical applications. Scientists are researching the use of electronic noses to diagnose illness by smelling patients' breath with the possibility of installing tiny electronic noses in phone receivers, so that patients can simply breathe into the phone and wait for a diagnosis. High-tech snifters may be used not just for breath-smelling but also to detect other subtle changes in body odor that can indicate disease conditions (Wongchoosuk et al., 2009; Myrick et al., 2009; Tang et al., 2010; Jha and Yaava, 2011; Bucak and Karlık, 2009; Huang and Wan, 2009; Zeng et al., 2009; Lange et al., 2009; Vera et al., 2011; Song et al., 2011).

Just like the human olfactory system, electronic noses do not need to be specially designed to detect a particular volatile. In fact, they can learn new patterns and associate them with new odors through training and data storage functions as humans do. However, training of electronic noses based on sensory panel classifications is required in order to obtain meaningful classifications.

Our unique personal body-odor may also become an alternative form of identification, signaling the end of credit-card fraud, forgotten or misappropriated PIN numbers, fake ID cards, among others. Electronic noses in banks and companies may soon be able to replace security entry systems involving cards and codes with a device that recognizes each employee's personal odor.

In this study a novel approach to odor recognition and classification using Nested-XOR function with Recursion is presented using a multi-sensor nose system. The study will prove that derived odors can be 
related to the original one and any simulated nonoriginal odor can be traced back and uncovered.

\section{MATERIALS AND METHODS}

The main components of the system (Fig. 1) are:

- The sensing system

- The automated pattern recognition system

Generally speaking, the odor system shown in Fig. 1 collects a sample and routes it through a sensor array where the presence of certain substances are detected. The concentrations of these substances are recorded as an along voltage signals. To accomplish this function, a mechanical system draws the sample through the sensor array and then expels it from the remote unit. This system also provides a source of air to flush the sensors in between sampling periods.

This combination of tuned sensors coupled with sophisticated information processing makes the electronic nose a powerful instrument for odor analysis applications. Each odorant presented to the sensor array produces a signature or characteristic pattern of the odorant (Baldwin et al., 2011; Huan et al., 2011; Colea et al., 2011; Im et al., 2011 Phaisangittisagul and Nagle, 2011).

Our Multi-Sensor array system employs MOSbased sensors with an $\mathrm{SnO} 2$ metal-oxide semiconducting film coated onto a ceramic substrate Each device also contains a heating element. Oxygen from the air is dissolved in the semiconductors' lattice, setting its electrical resistance to a background level (stable when at equilibrium). During the measurement, the volatile molecules (mainly non-polar) are adsorbed at the surface of the semiconductor where they react (oxidation/reduction) with the dissolved oxygen species causing a further modification of the resistance (or conductivity) of the device. This last change is taken as the response of the system to that particular sample.

By presenting many different odorants to the sensor array, a database of signatures is built up. This database of odorant signatures is then used to build the odor recognition system. The goal of this process is to train or configure the recognition system to produce unique classifications or clustering's of each odorant so that an automated identification can be implemented. During testing operation, a chemical vapor or odor is blown over the sensor array, the sensor signals are digitized and fed into the computer, with intelligent classification algorithm used to identify the odor and its relation to other odors (Haddi et al., 2011; Wen and Tian-Mo, 2010; Iskandarani, 2010; Alizadeh, 2010; Musatov et al., 2010). Consider a classification problem where a test pattern is to be assigned to a class label (Odor Class), OC where Eq. 1:

$\mathrm{OC} \in\left\{\mathrm{OC}_{1}, \mathrm{OC}_{2}, \ldots, \mathrm{OC}_{\mathrm{n}}\right\}$

$\mathrm{n}$ : Number of possible classes.

Measuring the test pattern is carried out by means of $\mathrm{M}$ sensors. Assume that the observations on the test pattern from the ith sensor are represented by the feature vector $S_{i}(i=1 \ldots m)$, which can be assumed a row vector. The objective now is to map $S_{i}(i=1 \ldots m)$ to a pattern class OC.

$S_{i}$ can be considered an estimation of the test pattern's characters using the i-th sensor. Different sensors probably give different measurements due to the factors of sensor type, position, sensitivity, while measuring same odor and describing the same test pattern. So there must be some kind of inherent relationship among them.

We define $\mathrm{S}_{0}$ as the Center-Feature (CF) which is the default and intrinsic response of the test pattern's characters, which is a priori feature. Hence, there is a functional relationship $T_{i}$ between $S_{0}$ and $S_{i}$. So Eq. 2:

$\mathrm{S}_{\mathrm{i}}=\mathrm{T}_{\mathrm{i}}\left(\mathrm{S}_{0}\right)$

$\mathrm{T}_{\mathrm{i}}$ : Transformation Function (TF).

Using $C F$ and $T F$, the observation set $\left\{S_{1}, \ldots . . S_{m}\right\}$ can be re-written as Eq. 3:

$\left\{\mathrm{T} 1\left(\mathrm{~S}_{0}\right), \ldots . . \mathrm{T}_{\mathrm{m}}\left(\mathrm{S}_{0}\right)\right\}$

which is the mapping from the observation set to the pattern class label OC.

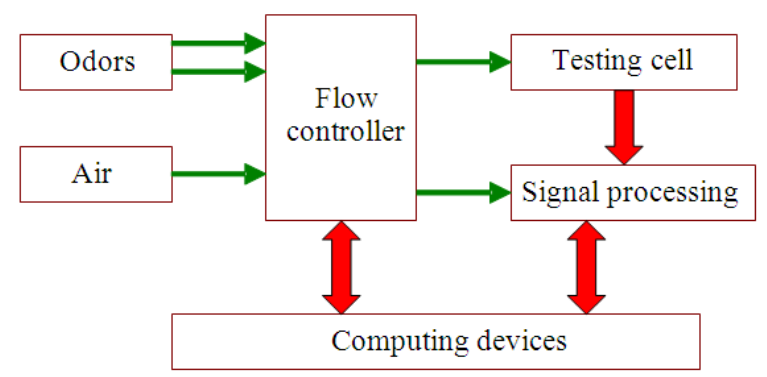

Fig. 1: Multi-sensor odor testing system 


\section{RESULTS}

Table 1 present the obtained practical measurements for seven odors, four of which are not related and three are related in a way that the presented system and technique will uncover. The developed system proved that not all similar results obtained through practical measurements are related.

\begin{tabular}{|c|c|c|c|c|c|c|c|}
\hline \multirow{2}{*}{$\begin{array}{l}\text { Time } \\
(\mathrm{sec})\end{array}$} & \multicolumn{7}{|c|}{ Number of response pulses $(\mathrm{N})$} \\
\hline & $\mathrm{O}_{1}$ & $\mathrm{O}_{2}$ & $\mathrm{O}_{3}$ & $\mathrm{O}_{4}$ & $\mathrm{O}_{5}$ & $\mathrm{O}_{6}$ & $\mathrm{O}_{7}$ \\
\hline 10 & 119 & 19 & 8 & 13 & 13 & 21 & 25 \\
\hline 20 & 145 & 25 & 10 & 18 & 17 & 40 & 40 \\
\hline 30 & 160 & 29 & 11 & 21 & 21 & 50 & 50 \\
\hline 40 & 169 & 30 & 11 & 24 & 22 & 54 & 55 \\
\hline 50 & 174 & 32 & 12 & 26 & 23 & 55 & 55 \\
\hline 60 & 178 & 34 & 13 & 27 & 24 & 56 & 60 \\
\hline
\end{tabular}

Table 2: Results of XOR function applied to odor data

\begin{tabular}{|c|c|c|c|c|c|c|}
\hline $\mathrm{T}$ & ${ }^{0} 1^{0} 2$ & ${ }^{0} 1^{0}{ }^{0} 3$ & ${ }^{0} 1^{0} 4$ & ${ }^{0} 1^{0} 5$ & ${ }^{0} 1^{0} 6$ & ${ }^{0} 1^{0} 7$ \\
\hline 10 & 100 & 127 & 122 & 122 & 98 & 110 \\
\hline 20 & 136 & 155 & 131 & 128 & 185 & 185 \\
\hline 30 & 189 & 171 & 181 & 181 & 146 & 146 \\
\hline 40 & 183 & 162 & 177 & 191 & 159 & 158 \\
\hline 50 & 142 & 162 & 180 & 185 & 153 & 153 \\
\hline \multirow[t]{32}{*}{60} & 144 & $\begin{array}{l}191 \\
{ }^{0} 2^{0} 3\end{array}$ & $\begin{array}{l}169 \\
{ }^{0} 2^{0} 4\end{array}$ & $\begin{array}{l}170 \\
02^{0} 5\end{array}$ & $\begin{array}{l}138 \\
{ }^{0} 2^{0} 6\end{array}$ & $\begin{array}{l}142 \\
{ }^{0} 2^{0} 7\end{array}$ \\
\hline & & 27 & 30 & 30 & 6 & 10 \\
\hline & & 19 & 11 & 8 & 49 & 49 \\
\hline & & 22 & 8 & 8 & 47 & 47 \\
\hline & & 21 & 6 & 55 & 40 & 41 \\
\hline & & 44 & 58 & 58 & 23 & 23 \\
\hline & & 47 & $\begin{array}{l}57 \\
{ }^{0} 3^{0} 4\end{array}$ & $\begin{array}{l}55 \\
{ }^{0} 3^{0} 5\end{array}$ & $\begin{array}{l}26 \\
{ }^{0} 3^{0} 6\end{array}$ & $\begin{array}{l}30 \\
{ }^{0} 3^{0} 7\end{array}$ \\
\hline & & & 5 & 5 & 29 & 17 \\
\hline & & & 24 & 27 & 34 & 34 \\
\hline & & & 30 & 30 & 57 & 57 \\
\hline & & & 19 & 29 & 61 & 60 \\
\hline & & & 22 & 27 & 59 & 59 \\
\hline & & & 22 & $\begin{array}{l}21 \\
04^{0} 5\end{array}$ & $\begin{array}{l}53 \\
{ }^{0} 4^{0} 6\end{array}$ & $\begin{array}{l}49 \\
{ }^{0} 4^{0} 7\end{array}$ \\
\hline & & & & 0 & 24 & 20 \\
\hline & & & & 3 & 58 & 58 \\
\hline & & & & 0 & 39 & 39 \\
\hline & & & & 14 & 46 & 47 \\
\hline & & & & 13 & 45 & 45 \\
\hline & & & & 3 & $\begin{array}{l}35 \\
{ }^{0} 5^{0} 6\end{array}$ & $\begin{array}{l}39 \\
{ }^{0} 5^{0} 7\end{array}$ \\
\hline & & & & & 24 & 20 \\
\hline & & & & & 57 & 57 \\
\hline & & & & & 39 & 39 \\
\hline & & & & & 32 & 33 \\
\hline & & & & & 32 & 32 \\
\hline & & & & & 32 & 36 \\
\hline & & & & & & ${ }^{0} 6^{0} 7$ \\
\hline & & & & & & 12 \\
\hline & & & & & & 0 \\
\hline & & & & & & 0 \\
\hline & & & & & & 1 \\
\hline & & & & & & 0 \\
\hline & & & & & & 4 \\
\hline
\end{tabular}

Table 2 shows results of applying XOR arithmetical function to the obtained data.

The used notation is:

$$
\begin{aligned}
& \mathrm{o}_{\mathrm{i}}: \text { odor }_{\mathrm{i}} \\
& \mathrm{o}_{\mathrm{j}} \text { odor }_{\mathrm{j}} \\
& \mathrm{o}_{\mathrm{l}} \mathrm{o}_{\mathrm{m}}(\text { odor key }): \operatorname{XOR}\left(\mathrm{o}_{\mathrm{i}}, \mathrm{o}_{\mathrm{j}}\right)
\end{aligned}
$$

Table 2 presnets the first row as the parent one with subsequent rows presenting the off springs, where each subsequent row is a parent of the row that follows it. This inheritance property through nesting of the developed technique allows the uncovering of original (parents) odors and the ones derived or made using some of the original odor features.

\section{DISCUSSION}

From Table 2 it is realized that to obtain an accurate, valid, reliable classification, Eq. 4-6 are applied:

odor key $_{\text {nest }}=\mathrm{y}_{\text {nest }}=\operatorname{XOR}\left(\mathrm{o}_{1}, \mathrm{o}_{\mathrm{m}}\right)$

odor key $_{\text {sub }}=\mathrm{y}_{\text {sub }}=\left|\mathrm{o}_{1}-\mathrm{o}_{\mathrm{m}}\right|$

Classify $\left.=\operatorname{correlate}\left(\mathrm{y}_{\text {nest }}, \mathrm{y}_{\text {sub }}\right)\right)$

The individual results are shown in matrices 7-36:

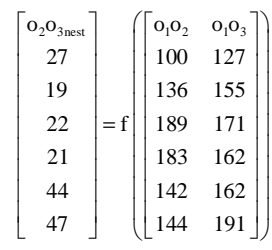

$\left[\begin{array}{c}\mathrm{o}_{2} \mathrm{o}_{3 \text { sub }} \\ 27 \\ 19 \\ 18 \\ 21 \\ 20 \\ 47\end{array}\right]=\mathrm{f}\left(\left[\begin{array}{cc}\mathrm{o}_{1} \mathrm{o}_{2} & \mathrm{o}_{1} \mathrm{o}_{3} \\ 100 & 127 \\ 136 & 155 \\ 189 & 171 \\ 183 & 162 \\ 142 & 162 \\ 144 & 191\end{array}\right]\right)$

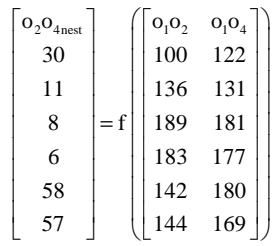


Am. J. Applied Sci., 8 (9): 910-917, 2011
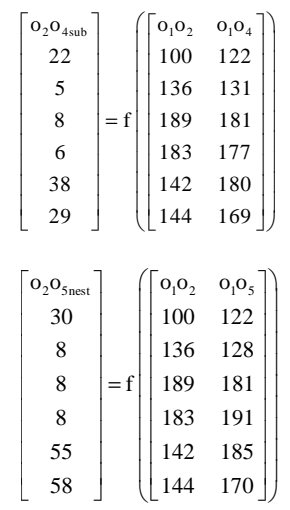

$\left[\begin{array}{c}\mathrm{o}_{2} \mathrm{o}_{5 \text { sub }} \\ 22 \\ 8 \\ 8 \\ 8 \\ 43 \\ 26\end{array}\right]=\mathrm{f}\left(\left[\begin{array}{cc}\mathrm{o}_{1} \mathrm{o}_{2} & \mathrm{o}_{1} \mathrm{o}_{5} \\ 100 & 122 \\ 136 & 128 \\ 189 & 181 \\ 183 & 191 \\ 142 & 185 \\ 144 & 170\end{array}\right]\right)$

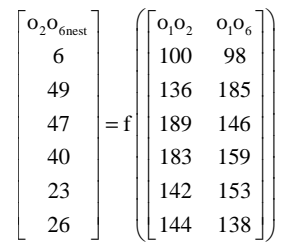

$\left[\begin{array}{c}\mathrm{o}_{2} \mathrm{o}_{6 \text { sub }} \\ 2 \\ 49 \\ 43 \\ 24 \\ 13 \\ 6\end{array}\right]=\mathrm{f}\left(\left[\begin{array}{cc}\mathrm{o}_{1} \mathrm{o}_{2} & \mathrm{o}_{1} \mathrm{o}_{6} \\ 100 & 98 \\ 136 & 185 \\ 189 & 146 \\ 183 & 159 \\ 142 & 153 \\ 144 & 138\end{array}\right]\right)$
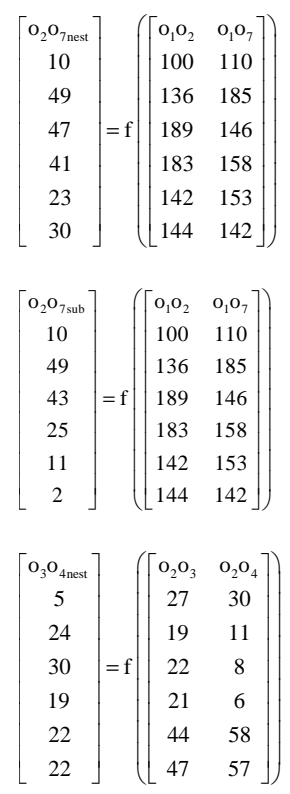

(10)

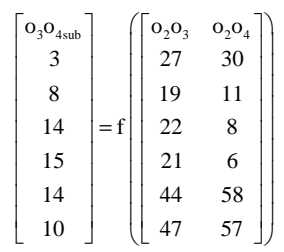

(11)

$\left[\begin{array}{c}\mathrm{o}_{3} \mathrm{o}_{5 \text { nest }} \\ 5 \\ 27 \\ 30 \\ 29 \\ 27 \\ 21\end{array}\right]=\mathrm{f}\left(\left[\begin{array}{cc}\mathrm{o}_{2} \mathrm{o}_{3} & \mathrm{o}_{2} \mathrm{o}_{5} \\ 27 & 30 \\ 19 & 8 \\ 22 & 8 \\ 21 & 8 \\ 44 & 55 \\ 47 & 58\end{array}\right]\right)$

(12)

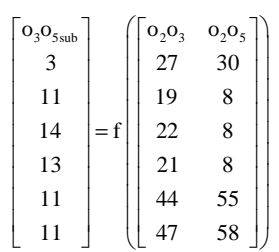

(13)

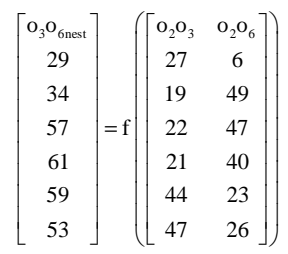

(14)

$\left[\begin{array}{c}\mathrm{o}_{3} \mathrm{o}_{6 \text { sub }} \\ 21 \\ 30 \\ 25 \\ 19 \\ 21 \\ 21\end{array}\right]=\mathrm{f}\left(\left[\begin{array}{cc}\mathrm{o}_{2} \mathrm{o}_{3} & \mathrm{o}_{2} \mathrm{o}_{6} \\ 27 & 6 \\ 19 & 49 \\ 22 & 47 \\ 21 & 40 \\ 44 & 23 \\ 47 & 26\end{array}\right]\right)$

(15)

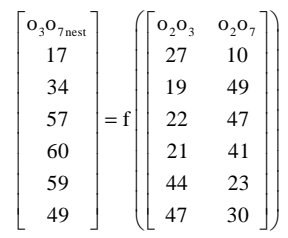

(16)

$\left[\begin{array}{c}\mathrm{o}_{3} \mathrm{o}_{7 \text { sub }} \\ 17 \\ 30 \\ 25 \\ 20 \\ 21 \\ 17\end{array}\right]=\mathrm{f}\left(\left[\begin{array}{cc}\mathrm{o}_{2} \mathrm{o}_{3} & \mathrm{o}_{2} \mathrm{o}_{7} \\ 27 & 10 \\ 19 & 49 \\ 22 & 47 \\ 21 & 41 \\ 44 & 23 \\ 47 & 30\end{array}\right]\right)$

(17)

$\left[\begin{array}{c}\mathrm{o}_{4} \mathrm{o}_{5 \text { nest }} \\ 0 \\ 3 \\ 0 \\ 14 \\ 13 \\ 3\end{array}\right]=\mathrm{f}\left(\left[\begin{array}{cc}\mathrm{o}_{3} \mathrm{o}_{4} & \mathrm{o}_{3} \mathrm{o}_{5} \\ 5 & 5 \\ 24 & 27 \\ 30 & 30 \\ 19 & 29 \\ 22 & 27 \\ 22 & 21\end{array}\right]\right)$

(18) 
Am. J. Applied Sci., 8 (9): 910-917, 2011
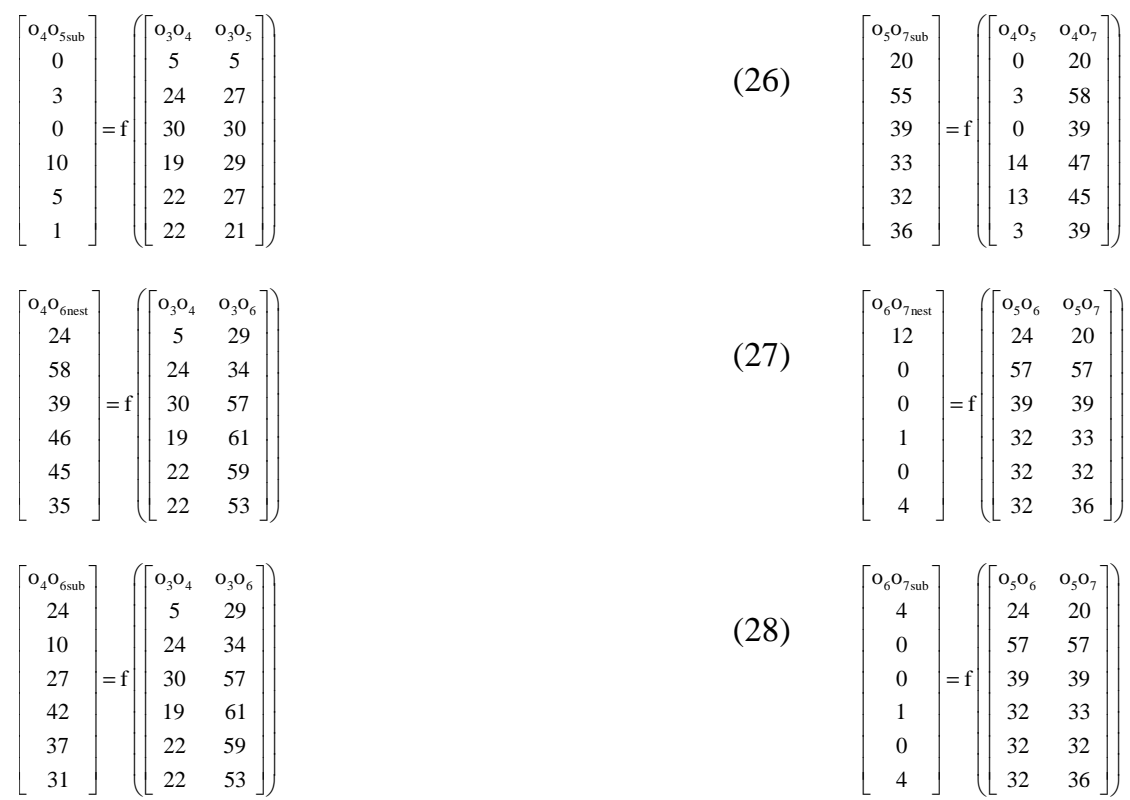

$\left[\begin{array}{c}\mathrm{o}_{6} \mathrm{o}_{7 \text { sub }} \\ 4 \\ 0 \\ 0 \\ 1 \\ 0 \\ 4\end{array}\right]=\mathrm{f}\left(\left[\begin{array}{cc}\mathrm{o}_{5} \mathrm{o}_{6} & \mathrm{o}_{5} \mathrm{o}_{7} \\ 24 & 20 \\ 57 & 57 \\ 39 & 39 \\ 32 & 33 \\ 32 & 32 \\ 32 & 36\end{array}\right]\right)$
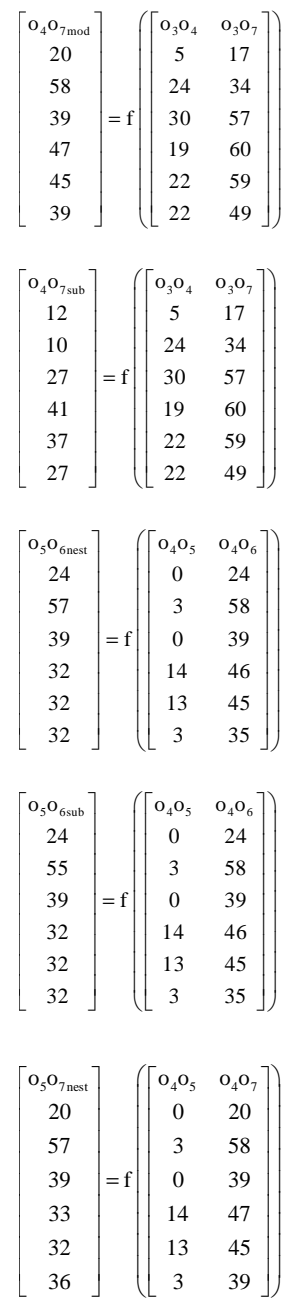

The required conditions for an odor to belong to the same class and to exhibit inheritance features in the designed classifier are:

- Most features in Eq. 4 to be equal to Eq. 5

- No discontinuity or abrupt transition in the features between Eq. 4 and 5

- No zero features in common per parent between Eq. 4 and Eq. 5

- The inheritance combinations is shown in Fig. 2

These applied conditions produce the following classifying maps:

- Mapping of the number of common features produced by Eq. 4 and 5. The maximum number of common features is shown to be between odors 5 , 6 and 7, as presented in Fig. 3

- Mapping of discontinuities and the presence of zeros (no shared features at all). Odors 5, 6 and 7 showed neither discontinuities nor zeros among their shared features. This is presented in Fig. 4

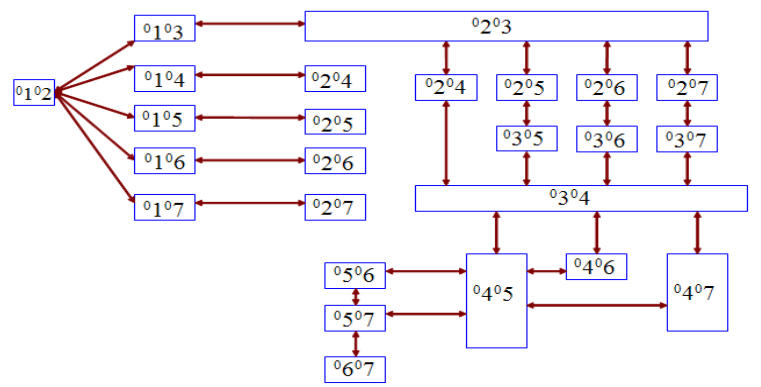

Fig. 2: Odor inheritance and classification chart 914 


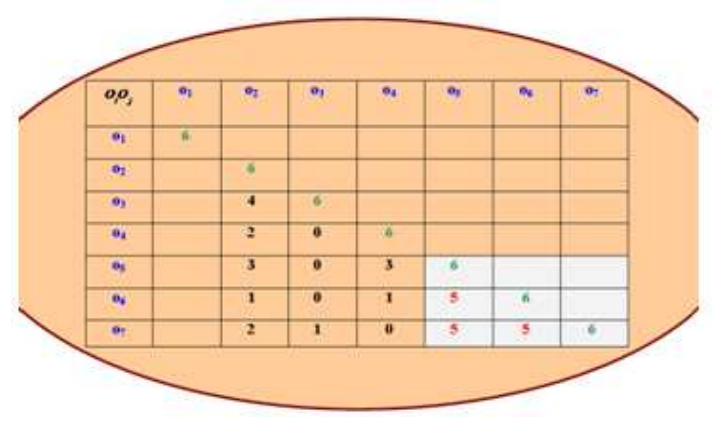

Fig. 3: Odor Common features map

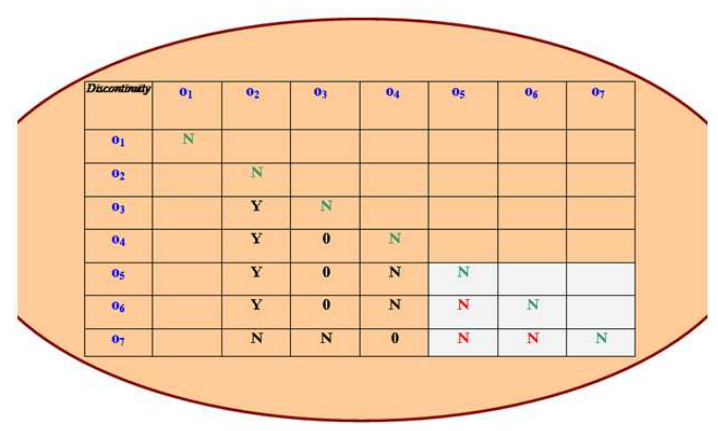

Fig. 4: Odor features discontinuity map

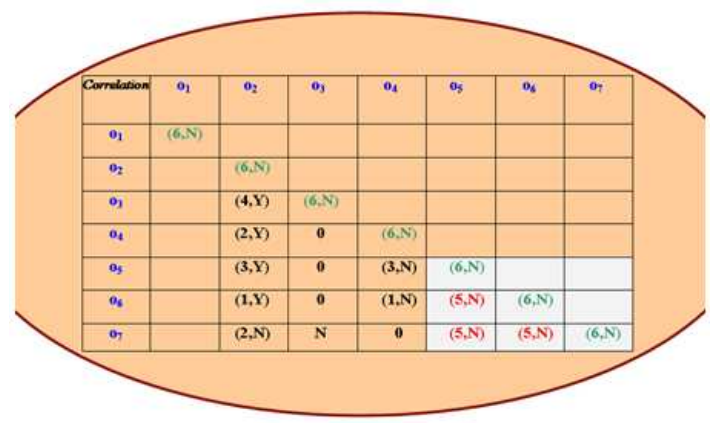

Fig. 5: Odor features correlation map

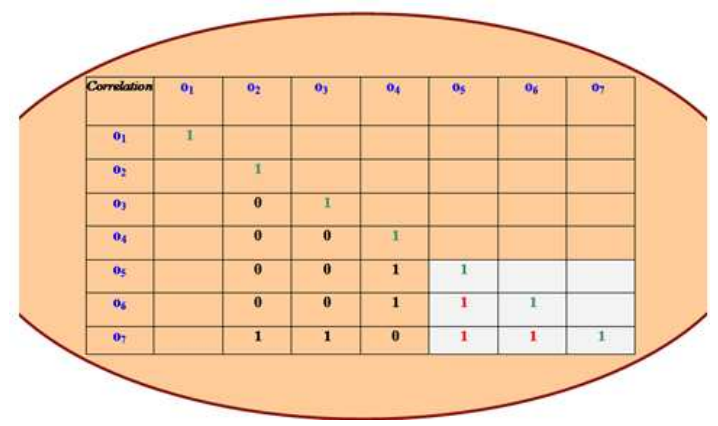

Fig. 6: Odor features correlation map

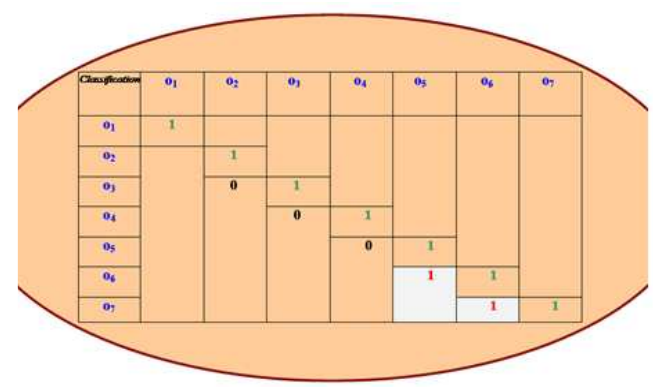

Fig. 7: Odor final classification map

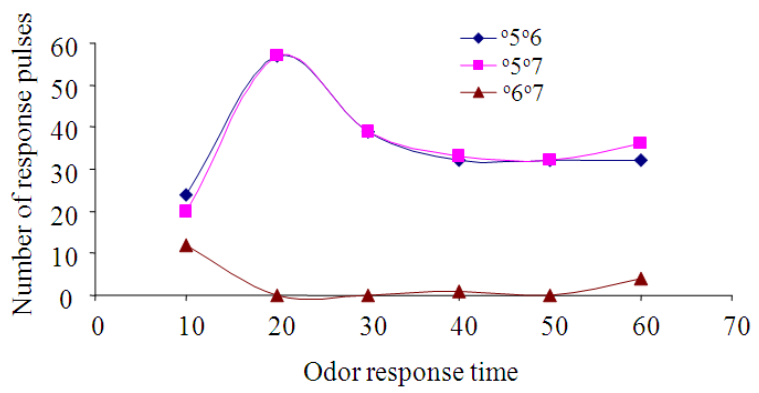

Fig. 8: Relationship between related odors

To achieve final classification, both maps in Fig. 3 and Fig. 4 are superimposed on each other and results are correlated to produce the final and correlation map, as shown in Fig. 5 and 6.

Applying AND function between each pair results in the correlation map in Fig. 6.

The maps in Figs. 5 and 6 show clearly odors 5, 6 and 7 to be related with one as the original and the other two are imitated or derived from the first. Now, after reaching this result, the types of the 7 odors are uncovered to find out:

- Odors 1, 2, 3 and 4 are all original but different types of odors

- Odors 5,6 and 7: Odor 6 is the original with odors 5 and 7 derived from odor 6 by ratios Eq. 37:

$\mathrm{o}_{5}=0.33 * \mathrm{o}_{6}$

$\mathrm{o}_{7}=0.67 * \mathrm{o}_{6}$

Equation 38 explains the close results between odor 6 and odor 7 as most of the features of odor 6 is transferred to odor 7 due to the large percentage of odor 6 in odor 7.

Figure 7 shows the final classification result using a NAND function between each row and the next, with Fig. 8 illustrating the relationships between $\mathrm{o}_{5}, \mathrm{o}_{6}$ and $\mathrm{o}_{7}$. 
As both $\mathrm{o}_{5}$ and $\mathrm{o}_{7}$ are derived from $\mathrm{o}_{6}$, then the missing feature must be shared with the substance or substances added to the material that produced the new apparently similar odor.

\section{CONCLUSION}

The designed multi-sensor nose proved to be sensitive to a wide range of odors and together with the developed technique proved to be a successful device for odor originality classification. The presented system is useful when the sensor array is exposed to target odor samples that results in the generation of response patterns. Such patterns are analyzed by the developed algorithm using nesting and inheritance techniques that determine odor class identities through correlation of detected properties. The potential applications of such system with its nesting and inheritance features are:

- Perfume making and checking against fake fragnance

- Checking freshness of fruits, fish and meat.

- Illness diagnosis through smelling of patient breath

- Preganancy detection

- Ovultion detection for fertility treatment and birth control

- Detection of subtle changes in body odor that might indicate disease condition

- Biometric applications for identification to prevent fraud

- Automotive security systems

- Environmental Monitoring

- Air Quality and safety

- Pharmaceutical products

- Military applications and explosives detection

\section{REFERENCES}

Alizadeh, T., 2010. Chemiresistor sensors array optimization by using the method of coupled statistical techniques and its application as an electronic nose for some organic vapors recognition. Sensors Actuators B: Chemi., 2: 740749. DOI: $10.1016 /$ j.snb.2009.10.018

Baldwin, E.A., J. Bai, A. Plotto and S. Dea, 2011. Electronic noses and tongues: Applications for the food and pharmaceutical industries. Sensors, 11: 4744-4766. DOI: 10.3390/s110504744
Bucak, I.O. and B. Karlı, 2009. Hazardous odor recognition by cmac based neural networks. Sensors, 9: 7308-7319. DOI: 10.3390/s90907308

Colea, M., J.A. Covingtona and J.W. Gardner, 2011. Combined electronic nose and tongue for a flavour sensing system. Sensors Actuators B Chem., 2: 832-839. DOI: 10.1016/j.snb.2011.02.049

Haddi, Z., A. Amari, H. Alami, N.E. Bari and E. Llobet et al., 2011. A portable electronic nose system for the identification of cannabis-based drugs. Sensors Actuators B: Chemi., 155: 456-463. DOI: 10.1016/j.snb.2010.12.047

Huan, C., L. Zhiyua and F. Ganga, 2011. Analysis of the aging characteristics of $\mathrm{SnO} 2$ gas sensors. Sensors Actuators B Chem., 156: 912-917. DOI: 10.1016/j.snb.2011.03.005

Huang, J. and Q. Wan, 2009. Gas sensors based on semiconducting metal oxide one-dimensional nanostructures. Sensors, 9: 9903-9924. DOI: $10.3390 / \mathrm{s} 91209903$

Im, J., S. Sengupta, M. Baruch, C.D. Granz and S. Ammu et al., 2011. A hybrid chemiresistive sensor system for the detection of organic vapors. Sensors Actuators B: Chem., 156: 715-722. DOI: 10.1016/j.snb.2011.02.025

Iskandarani, M.Z., 2010. A novel odor key technique for security applications using electronic nose system. Am. J. Applied Sci., 8: 1118-1122. DOI: 10.3844/ajassp.2010.1118.1122

Jha, S.K. and R.D.S. Yaava, 2011. Power scaling of chemiresistive sensor array data for odor classification. J. Patt. Recog. Res., 1: 65-74.

Lange, U., N.V. Roznyatovskaya and V.M. Mirsky, 2009. Conducting polymers in chemical sensors and arrays. Anal. Chim. Acta, 614: 1-26. DOI: 10.1016/j.aca.2008.02.068

Musatov, V.Y., V.V. Sysoev, M. Sommer and I. Kiselev, 2010. Assessment of meat freshness with metal oxide sensor microarray electronic nose: A practical approach. Sensors Actuators B: Chemi., 144: 99-103. DOI: 10.1016/j.snb.2009.10.040

Myrick, A.J., K.C. Park, J.R. Hetling and T.C. Baker, 2009. Detection and discrimination of mixed odor strands in overlapping plumes using an insectantenna-based chemosensor system. J. Chem. Ecol., 35: 118-130. DOI: 10.1007/s10886-0089582-4

Phaisangittisagul, E. and H. Nagle, 2011. Predicting odor mixture's responses on machine olfaction sensors. Sensors Actuators B Chem., 155: 473-482. DOI: $10.1016 /$ j.snb.2010.12.049 
Song, K., Q. Liu and Q. Wang, 2011. Olfaction and hearing based mobile robot navigation for odor/sound source search. Sensors, 11: 2129-2154. DOI: $10.3390 / \mathrm{s} 110202129$

Tang, K.T., S.W. Chiu, C.H. Pan, H.Y. Hsieh and Y.S. Liang et al., 2010. Development of a portable electronic nose system for the detection and classification of fruity odors. Sensors, 10: 91799193. DOI: $10.3390 / \mathrm{s} 101009179$

Vera, L., L. Acena, J. Guasch, R. Boque and M. Mestres et al., 2011. Characterization and classification of the aroma of beer samples by means of an MS e-nose and chemometric tools. Anal. Bioan. Chem., 399: 2073-2081. DOI: 10.1007/s00216-010-4343-y
Wen, Z. and L. Tian-Mo, 2010. Gas-sensing properties of $\mathrm{SnO}_{2}-\mathrm{TiO}_{2}$-based sensor for volatile organic compound gas and its sensing mechanism. Physica B: Phys. Condensed Matter, 405: 1345-1348. DOI: 10.1016/j.physb.2009.11.086

Wongchoosuk, C., M. Lutz and T. Kerdcharoen, 2009. Detection and classification of human body odor using an electronic nose. Sensors, 9: 7234-7249. DOI: $10.3390 / \mathrm{s} 90907234$

Zeng, W., T. Liu, Z. Wang, S. Tsukimoto and M. Saito et al., 2009. Selective detection of formaldehyde gas using a cd-doped $\mathrm{tio}_{2}-\mathrm{SnO}_{2}$ sensor. Sensors, 9: 9029-9038. DOI: $10.3390 / \mathrm{s} 91109029$ 